\title{
The fast development of solar terrestrial sciences in Taiwan
}

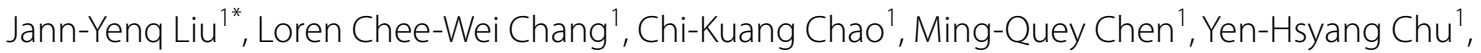 \\ Lin-Ni Hau', Chien-Ming Huang ', Cheng-Ling Kuo', Lou-Chuang Lee', Ling-Hsiao Lyu' ', Chia-Hsien Lin', \\ Chen-Jeih Pan' ${ }^{1}$, Jih-Hong Shue ${ }^{1}$, Ching-Lun Su' ${ }^{1}$ Lung-Chih Tsai ${ }^{1}$, Ya-Hui Yang ${ }^{1}$, Chien-Hung Lin², Rue-Ron Hsu² \\ and Han-Tzong Su
}

\begin{abstract}
In Taiwan, research and education of solar terrestrial sciences began with a ground-based ionosonde operated by Ministry of Communications in 1952 and courses of ionospheric physics and space physics offered by National Central University (NCU) in 1959, respectively. Since 1990, to enhance both research and education, the Institute of Space Science at NCU has been setting up and operating ground-based observations of micropulsations, very high-frequency radar, low-latitude ionospheric tomography network, high-frequency Doppler sounder, digital ionosondes, and total electron content (TEC) derived from ground-based GPS receivers to study the morphology of the ionosphere for diurnal, seasonal, geophysical, and solar activity variations, as well as the ionosphere response to solar flares, solar wind, solar eclipses, magnetic storms, earthquakes, tsunami, and so on. Meanwhile, to have better understanding on physics and mechanisms, model simulations for the heliosphere, solar wind, magnetosphere, and ionosphere are also introduced and developed. After the 21 September 1999 Mw7.6 Chi-Chi earthquake, seismo-ionospheric precursors and seismo-traveling ionospheric disturbances induced by earthquakes become the most interesting and challenging research topics of the world. The development of solar terrestrial sciences grows even much faster after National Space Origination has been launching a series of FORMOSAT satellites since 1999. ROCSAT-1 (now renamed FORMOSAT-1) measures the ion composition, density, temperature, and drift velocity at the $600-\mathrm{km}$ altitude in the low-latitude ionosphere; FORMOSAT-2 is to investigate lightning-induced transient luminous events, polar aurora, and upper atmospheric airglow, and FORMOSAT-3 probes ionospheric electron density profiles of the globe. In the near future, FORMOSAT-5 and FORMOSAT-7/COSMIC-2 will be employed for studying solar terrestrial sciences. These satellite missions play an important role on the recent development of solar terrestrial sciences in Taiwan.
\end{abstract}

\section{Introduction}

Ionospheric observation and investigation in Taiwan were initiated in 1951 when a manual ionosonde was first operated by National Taiwan University. The routine observation of the ionosphere in Taiwan was started in 1952 by the Radio Research Laboratory of the Ministry of Communications. In 1966, the ionospheric sounding station was moved from Taipei to Chung-Li, about $40 \mathrm{~km}$ southwest of Taipei, and the routine ionogram observations have continued without interruption. Usually, the

\footnotetext{
*Correspondence: jyliu@jupiter.ss.ncu.edu.tw

${ }^{1}$ National Central University, Taoyuan, Taiwan

Full list of author information is available at the end of the article
}

observations were made every $15 \mathrm{~min}$. The characteristics of the ionosphere have been routinely reduced in accordance with the "URSI (International Union of Radio Science) handbooks of ionogram interpretation and reduction." Meanwhile, Lungping magnetic observatory was established and operated by Ministry of Communication since 1965. Later, routine sunspot, total electron content, and HF Doppler frequency shift observations were also carried out at the observatory. However, all the observations were gradually terminated due to severe damage by the 21 September 1999 M7.6 Chi-Chi earthquake.

Meanwhile, after the International Geophysical Year (IGY) in 1957-1958, solar terrestrial education in Taiwan 
was initiated by Institute of Geophysics, National Central University (NCU) at Maio-Li in 1959. NCU was moved from Maio-Li to Chung-Li in 1970, and the solar terrestrial education was then taken over by Department of atmospheric physics. Both micropulsation and HF Doppler frequency shift observations were conducted in late 1980s. The very high-frequency (VHF) radar was set up Prof. Chao-Han Liu and has been operating since 1985 to probe the lower and middle atmosphere mainly, and the lower ionosphere. Institute of Space Science (ISS) at NCU was established for MS and Ph.D. program for the solar terrestrial education in 1990. Hereafter, educations for under and graduate programs as well as researches with observations, theoretical developments, and model simulations related to the solar, interplanetary space, magnetosphere, ionosphere, and upper neutral atmosphere have been mainly carrying out by NCU/ISS. In 1994, a laboratory-type advanced ionospheric sounder, Digisonde Portable Sounder (DPS), was set up on NCU campus, and later, a Dynasonde was also added.

After ROCSAT-1 (or FORMOSAT-1), FORMOSAT-2, and FORMOSAT-3/COSMIC (F3/C) were launched in 1999, 2004, and 2006 by National Space Organization, model developments and observations for ionospheric plasma structures, dynamics, and space weather have been significantly advanced. In this paper, recent progresses in VHF radar, solar-solar wind-magnetosphere, earthquake anomalies and disturbances, ionospheric space weather, and FORMOSAT satellites are summarized.

\section{Chung-Li radar VHF radar}

The Chung-Li VHF radar situated on the NCU campus (Fig. 1) has been operating since 1985 to probe the lower and middle atmosphere mainly, and the lower ionosphere. In the recent 5-year, for the lower atmosphere,

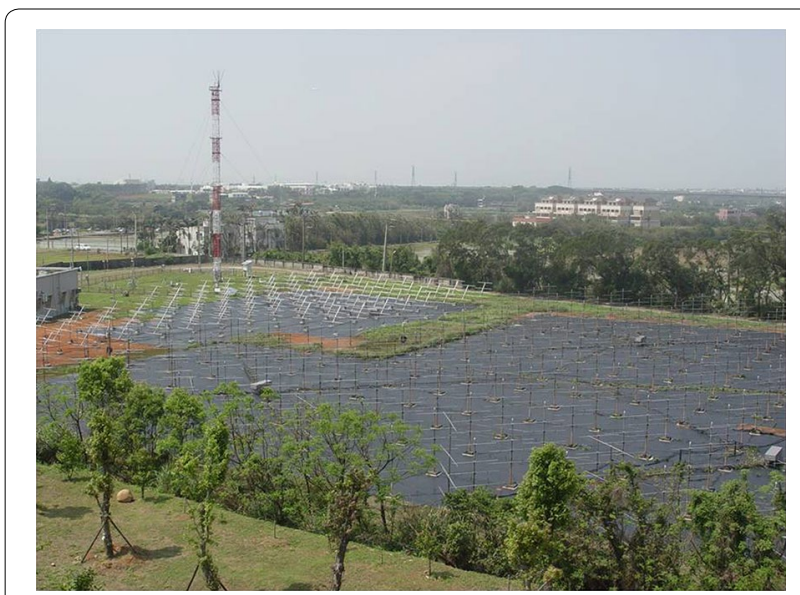

Fig. 1 Antenna arrays for the Chung-Li VHF radar on the NCU campus multi-receiver coherent radar imaging and multi-frequency range imaging are applied to observe smallscale structures in the troposphere and the field-aligned plasma irregularities in the ionosphere (Chen et al. 2014a, b, 2015).

A physical process is proposed to account for the relation between gravity wave-perturbed neutral wind and height variation of the Doppler velocity shear of the 3-m Es field-aligned irregularities (Chu et al. 2011). A technique of measuring aspect angle of radar returns from 3-m Es field aligned irregularities is developed. A longterm statistical analysis shows that the mean aspect angle of the 3-m Es field-aligned irregularities for the layer-type plasma structures is about $0.05^{\circ}$ smaller than that $\left(0.3^{\circ}\right)$ for the clump-type plasma structures (Wang et al. 2011). Interferometry measurements provide compelling evidences that the mechanisms responsible for the generations of the layer-type and clump-type plasma structures are, respectively, very likely ion convergence of tidal wind shear in a thin region and the wind shear associated with propagating gravity wave (Chu et al. 2013). F3/C measurements and model simulations both show that the summer maximum (winter minimum) in the Es layer occurrence is very likely attributed to the convergence of the $\mathrm{Fe}+$ concentration flux driven by the tidal wind in ionosphere (Chu et al. 2014). A new method is proposed to correct the phase bias in using range imaging technique to resolve fine atmospheric structure from pulse radar echoes (Chen et al. 2014b). With the Chung-Li VHF radar observation, it is found that the amplitudes of the mean wind, diurnal, and semidiurnal tides in height range $82-100 \mathrm{~km}$ are systematically larger than those of the model-predicted winds by up to a factor of $3 \mathrm{Su}$ et al. 2014). An algorithm for improving F3/C-retrieved $\mathrm{E}$ region electron density is proposed. After removing the IRI model-simulated GPS RO (radio occultation) retrieval errors from the original $\mathrm{F} 3 / \mathrm{C}$ measurements, the average values of the annual and monthly mean percentage errors of the $\mathrm{F} 3 / \mathrm{C}$-measured $\mathrm{RO}$ retrieval errors of the $\mathrm{E}$ region electron density can be substantially reduced (Wu et al. 2015).

\section{Solar-solar wind-magnetosphere}

While it is generally believed that the presence of magnetic field can modify the thermal properties of solar structure and that solar eruptions can reform the coronal magnetic field, little is known whether any relationship may exist between the subsurface thermal structure and the solar eruption. Lin (2014) investigates whether any detectable relationship exists between the productivity of solar eruptions and the thermal properties of the subsurface structures. The results indicated that some subsurface thermal disturbances are seen to increase 
with eruptivity indices among active regions with high eruptivity. On the other hand, Yang et al. (2014) attempt to characterize the flare initiation based on the processed Helioseismic and Magnetic Imager vector magnetograms, Atmospheric Imaging Assembly $1600 \AA$, and RHESSI hard X-ray observations.

The existence of non-thermal radiations from planets is common in the solar system, e.g., the decameter radiation from Jupiter and the auroral kilometric radiation from the Earth. The problem of non-thermal radiation from planets remained unsolved until cyclotron maser instability being proposed as the radiation mechanism (Wu and Lee 1979; Lee and Wu 1980). It not only predicts the growth of the $\mathrm{X}$ - and O-mode waves but is also an efficient mechanism for direct amplification of waves. This mechanism have also been applied to the generation of Z-and whistler-mode waves, in which these waves can, in turn, further accelerate electrons from a few hundreds of $\mathrm{keV}$ to $\mathrm{MeV}$ (Lee et al. 2012a, 2013a).

The presence of neutral particles may modify the wave frequency and cause damping of Alfvén waves. The effects on Alfvén waves depend on the ratio collision frequency to the Alfvén wave frequency. The dispersion relation of Alfvén waves for all values of first time that there is a "forbidden zone" in the parameter space, where the real frequency of Alfvén waves becomes zero (Weng et al. 2013).

The first statistical study on repetition periods of whistler-mode rising-tone chorus waves using data from the THEMIS satellite is preformed (Shue et al. 2015). It is found that the repetition periods observed on the nightside and dawnside are larger than those observed on the dayside and duskside. Based on the THEMIS data, Shue and Chao (2013) reported that the total pressure just outside the magnetopause is larger than that just inside the magnetopause, the magnetopause moves earthward, and vice versa, and Shue et al. (2011) study a ratio of the compressed magnetic field just inside the magnetopause to the purely dipolar magnetic field at the same position. They also found that the ratio is linearly proportional to the subsolar standoff distance of the magnetopause. Continuous efforts have been made on the structure and dynamics of earth's magnetopause by reconstructing the two-dimensional plasma and magnetic field configuration from satellite data. In particular, it has identified a few reconnection events with significant field aligned flow from THEMIS spacecraft which exhibit $\mathrm{X}$ lines and magnetic island signatures (Jao and Hau 2015). Both fluid theory and particle simulations are adopted to infer the role of fluid theory in the evolution process of electrostatic solitary waves (Wang and Hau 2015). Meanwhile, Kan et al. (2011) present a new M-I coupling model of substorm during southward IMF based on the THEMIS observations of two events on 1 March 2008.

\section{Precursors and disturbances of large earthquakes}

Many observations possibly related to seismo-lithospheric precursors of the earth's surface magnetic field (Liu et al. 2006a) and the GPS surface deformation, seismo-atmospheric precursors of the infrasound signal (Xia et al. 2011), and seismo-ionospheric precursors (SIPs) in the electron density profile (Liu et al. 2009), the electron temperature (Oyama et al. 2008), ion density (Oyama et al. 2011), and neutral temperature (Sun et al. 2011) probed by satellites have been reported. The total electron content (TEC) in the global ionosphere map (GIM) routinely published allows us to monitor temporal SIPs at a specific location and discriminate the observed SIPs (Liu et al. 2001, 2009, 2010a) from global effects, such as solar flares, magnetic storms, and so on. (Liu et al. 2004a). Statistical analyses for detecting both temporal and spatial precursors in the ionospheric TEC are developed (Liu et al. 2004b, 2010b). Meanwhile, ionospheric model simulations are also introduced to find causal mechanisms explaining the observed SIPs (Liu et al. 2011a).

The ionospheric density variations can be caused by earth surface charges/currents produced from electric currents associated with the stressed rock, leading to the lithosphere-atmosphere-ionosphere electric coupling. A model for the lithosphere-atmosphere-ionosphere system is formulated (Kuo et al. 2011, 2014), and a threedimensional ionosphere simulation code is then used to study the ionospheric dynamics. The results can explain the density anomalies at different magnetic latitudes.

Doppler sounders and ionosondes have been used to detect seismo-traveling ionospheric disturbances (STIDs) triggered by earthquakes and tsunami (Liu et al. 2006b; Liu and Sun 2011). STIDs in the total electron content are first reported during the Indian Ocean tsunami triggered by the 26 December 2004 M9.3 Sumatra-Andaman earthquake (Liu et al. 2006c). On the other hand, the origin of the tsunami is also for the first time being observed by dense ground-based GPS receivers in Taiwan and Japan during the 11 March 2011 M9.0 Tohoku earthquake (Liu et al. 2011b).

\section{FORMOSAT satellites}

FORMOSAT-1, -2 , and -3 have been in orbits, while FORMOSAT-5, and -7 will soon be launched in 2016 and 2017 for studying solar terrestrial sciences, respectively.

\section{FORMOSAT-1}

FORMOSAT-1 (was named ROCSAT-1) is a low-earthorbit scientific experimental satellite. Lockheed Martin's Athena-1 successfully launched the satellite from Cape Canaveral, Florida, to its final orbit on January 27, 1999 (Fig. 2). After launched into an altitude of $600 \mathrm{~km}$ 


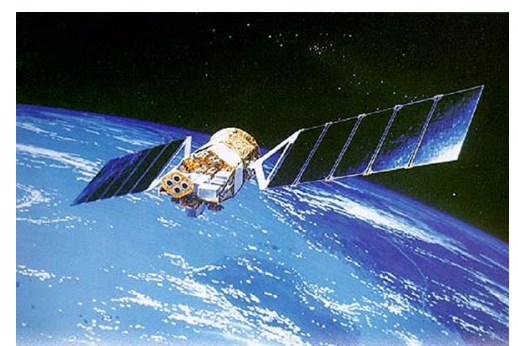

Fig. 2 Image of a flying simulation of FORMOSAT-1 and IPEI. IPEI is located at the front panel

with $35^{\circ}$ inclination, it circulates around the Earth every 97 min, transmitting collected data to Taiwan's receiving stations approximately six times a day. The ionospheric plasma and electrodynamics instrument (IPEI) onboard ROCSAT- 1 is designed to measure the ion composition, density, temperature, and drift velocity at the $600-\mathrm{km}$ altitude along the ROCSAT-1 orbit within the latitude band of $\pm 35^{\circ}$ of the low-latitude ionosphere (Fig. 2). It is a very successful mission, and more than 100 articles have been published in scientific journals with data from ROCSAT-1/IPEI. The main studies are classified as (1) ionospheric irregularities with high-resolution data (Chen et al. 2001, 2005; Su et al. 2001) (2) global distributions of ionospheric irregularities (Lee et al. 2005a, b; Su et al. 2006, 2007a, b, 2008, 2009, 2010), (3) low and mid-latitude ionospheric response to magnetic storm (Yeh et al. 2001, 2002, 2003, 2004, 2005a; Lee et al. 2004), and (4) models in the low- and mid-latitude ionosphere (Chao et al. 2003, 2004, 2010; Su et al. 2005b). To examine the low-latitude ionosphere dynamics, theoretical simulations of the disturbance dynamo mechanism are conducted by the TIEGCM (Huang et al. 2005; Huang and Chen 2008; Huang 2013), and the model simulations are cross compared with ROCSAT-1/IPEI and GIM TEC observations (Huang et al. 2008, 2010).

\section{FORMOSAT-2}

The FORMOSAT-2 satellite is launched on 16 January 2004 and is still in continuous operation. The scientific payload ISUAL (imager of sprites and upper atmospheric lightnings) onboard FORMOSAT-2 satellite is shown in Fig. 3). The scientific goals of this mission are to investigate lightning-induced transient luminous events (TLEs), polar aurora, and upper atmospheric airglow. The ISUAL scientific results include first global distributions and occurrence rates of TLEs (Chen et al. 2008), optical diagnose of energy in TLEs (Kuo et al. 2008), new category of gigantic jet (GJ) with negative and positive polarity (Chou et al. 2010), first finding of new sprites induced by the secondary GJs (Lee et al. 2013b), an evidence of identifying N2 Lyman-Birge-Hopfield emission as dim elves (Chang et al. 2010), and a positive correlation of TLEs response to ENSO in the coastal and the oceanic regions (Wu et al. 2012).

\section{FORMOSAT-3/COSMIC}

FORMOSAT-3/COSMIC (F3/C) consists of six microsatellites being successfully launched into a circular low Earth orbit at 0140 UTC on 15 April 2006. Each satellite houses a GPS occultation experiment (GOX) payload for the first time deriving the radio occultation (RO) vertical profile of electron density in the ionosphere uniformly and globally. By accumulating GOX observations, unprecedented detail of the three-dimensional (3D) ionospheric electron density structure can be constructed (Fig. 4) (Liu et al. 2010c).

Since 2009, an empirical and global ionospheric electron density $(\mathrm{Ne})$ model, the TaiWan Ionospheric Model (TWIM), has been proposed (Tsai et al. 2009), which exhibits vertical-fitted $\alpha$-Chapman-type layers with distinct F2, F1, E, and D layers and surface spherical harmonic approaches for the fitted layer parameters, including peak density, peak height, and scale height. To improve the TWIM into a real-time model, a time series autoregressive model to forecast short-term TWIM coefficients is also developed (Tsai et al. 2014a). The TWIM has been applied to determine ionospheric delay corrections for GPS positioning and for modeling performance evaluations and comparisons (Macalalad et al. 2012, 2014), locate a ground-based high-frequency (HF) radio transmitter using a numerical ray-tracing method (Tsai et al. 2014b), and improve the vertical ionospheric $\mathrm{Ne}$ profile retrieval of GPS radio occultation (RO) observations (Tsai et al. 2011).

The large amount of $\mathrm{F} 3 / \mathrm{C}$ ionospheric observations provides an excellent opportunity to study ionospheric tidal and planetary wave signatures. The global scale dynamics of the ionosphere have been linked to coupling phenomena from the neutral atmosphere below, solar and geomagnetic drivers from above, as well as in situ drivers, such as thermospheric winds and composition. Analysis of migrating tidal signatures in F3/C TECs (Chang et al. 2013a), as well as associated numerical experiments, yielded insight on the relations between ionospheric migrating tidal signatures and the corresponding features of zonal mean ionospheric local time variation isolated through such analysis. Such analysis is further extended to understanding the inter-annual variation of ionospheric tidal and stationary planetary waves (SPWs) signatures comprising the well-known "wave-4" modulation of the equatorial ionization anomalies (EIAs), a feature ultimately driven by modulation of the E-region dynamo by vertically propagating non-migrating 


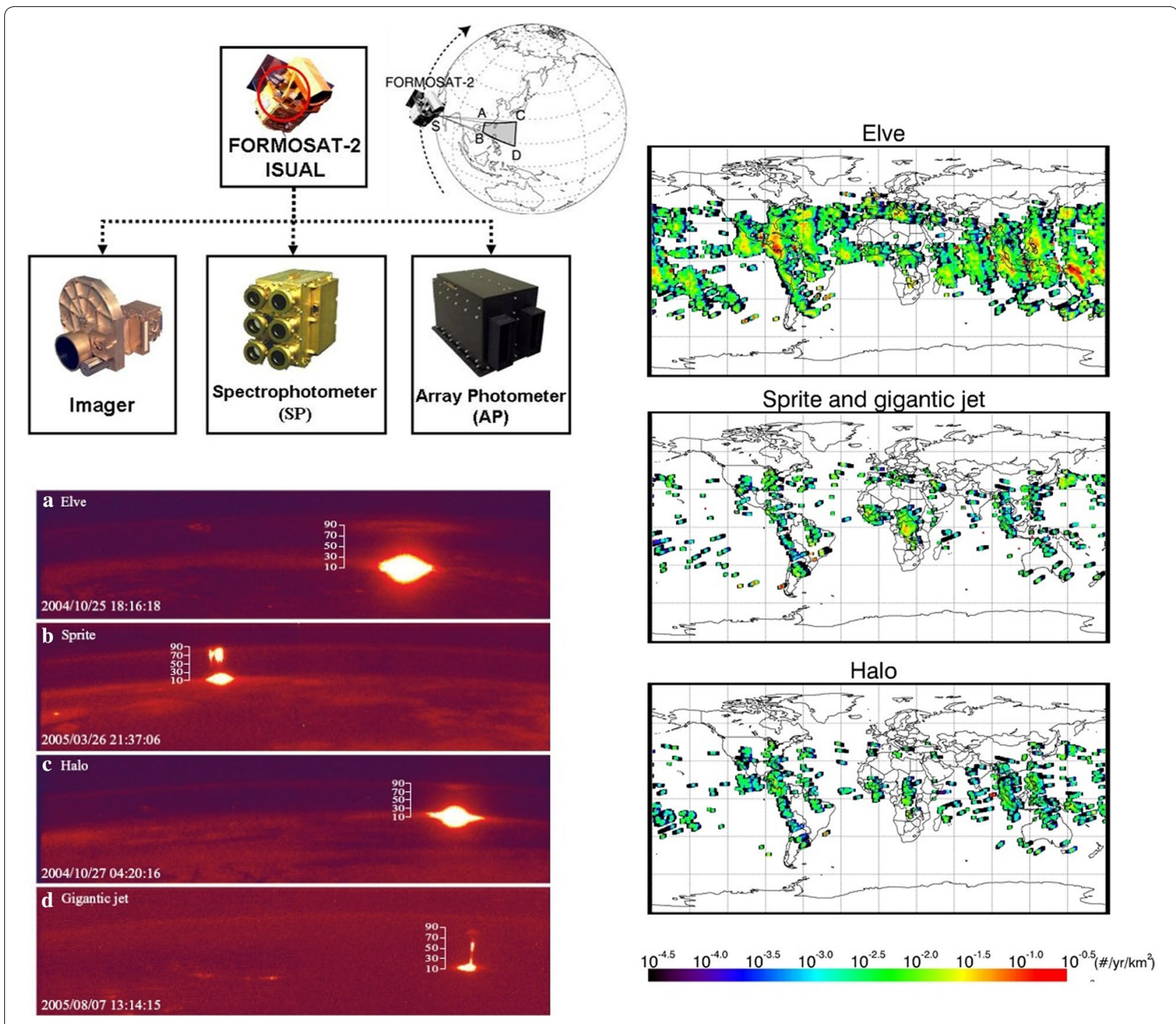

Fig. 3 Scientific payload ISUAL onboard FORMOSAT-2 satellite. The observed images and global distributions of Elve, Sprite, Halo, and Gigantic jet

atmospheric tides and SPWs (Chang et al. 2013b). The results demonstrated that such atmosphere-ionosphere coupling was present during periods of both high and low solar activities, forming a persistent feature of ionospheric variability. Such tidal/SPW analysis of F3/C ionospheric observations was also demonstrated (Chang et al. 2015a) to be effective in isolating the modes of variability comprising the Weddell Sea Anomaly (WSA).

The F3/C data are also useful for studying atmosphereionosphere coupling through the wind dynamo and mixing. Some tidal and planetary wave components are also capable of directly propagating into the thermosphere (Forbes et al. 2009). Breaking tides, planetary, and gravity waves can also induce changes to thermospheric and ionospheric composition through eddy mixing. Using TIMED satellite observations, as well as GPS TEC, it provided the first observational evidence that the mixing mechanism could produce significant short-term decreases in the thermospheric $\mathrm{O} / \mathrm{N} 2$ density ratio, as well as TEC during occurrences of the quasi-two-day planetary wave in the mesosphere and lower thermosphere (Chang et al. 2014). This result has highlighted the need for such mixing mechanisms to be considered in the context of short-term ionospheric variability.

The ionosphere electron density modification with wave-4 signature due to upward propagating tides can be clearly observed by F3/C (Lin et al. 2007a, b). The coupling goes further when the upper atmosphere 


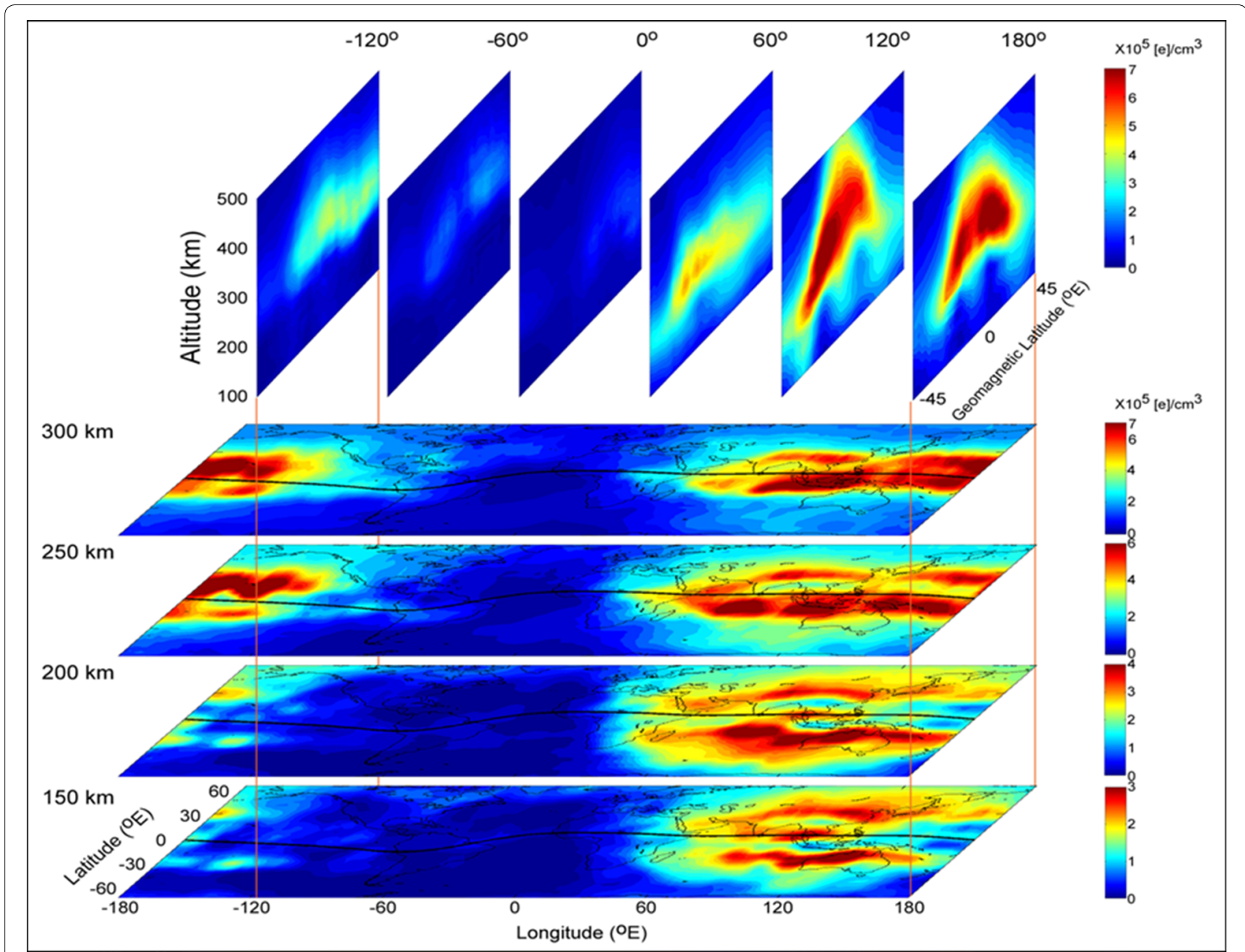

Fig. 4 Three-dimensional electron density structure observed by the F3/C at 0600 UT during April-June 2008 (Liu et al. 2010C)

community discovered that the high latitude stratosphere sudden warming (SSW) effect could disturb the equatorial ionospheric plasma structure. F3/C observation shows that the ionosphere modification due to SSW is through sun-synchronized atmospheric tides (Lin et al. 2012, 2013). Meanwhile, F3/C temperature has been employed to investigate Kelvin waves in the stratosphere (Pan et al. 2011) and global temperature in the stratosphere (Das and Pan 2014).

Scientists in Taiwan also discover new ionospheric plasma structure taking advantage of three-dimensional observation. From the first three-dimensional structure of ionospheric WSA, it can be realized that WSA is simpler part of a bigger ionospheric anomaly, namely, the middle latitude summer nighttime anomaly (MSNA) (Lin et al. 2009, 2010; Chen et al. 2011, 2013). Meanwhile, the MSNA/WSA eastward movement signature have also been comprehensively studied using F3/C observations (Lin et al. 2010; Liu et al. 2015; Chang et al. 2015b) and model simulations (Chen et al. 2011, 2013; Sun et al. 2015). Also, a new type of low latitude plasma structure located underneath the EIA peaks is discovered, and their corresponding physical mechanism is proposed for the first time (Lee et al. 2012b; Chen et al. 2014c).

\section{FORMOSAT-5}

The pronunciation of " 4 " in Chinese sounds like "death" or "bad luck", which is somewhat similar to "13" in West. Therefore, there is no FORMOSAT-4 mission. FORMOSAT-5 is a remote sensing satellite and scheduled to launch in 2016Q2 and anticipated to fly in a $98.28^{\circ}$ inclination sun-synchronous circular orbit at $720-\mathrm{km}$ altitude in the 1030/2230 LT sectors (Fig. 5). Advanced ionospheric probe (AIP) is an all-in-one plasma sensor to install on the FORMOSAT-5 satellite with sampling rate 

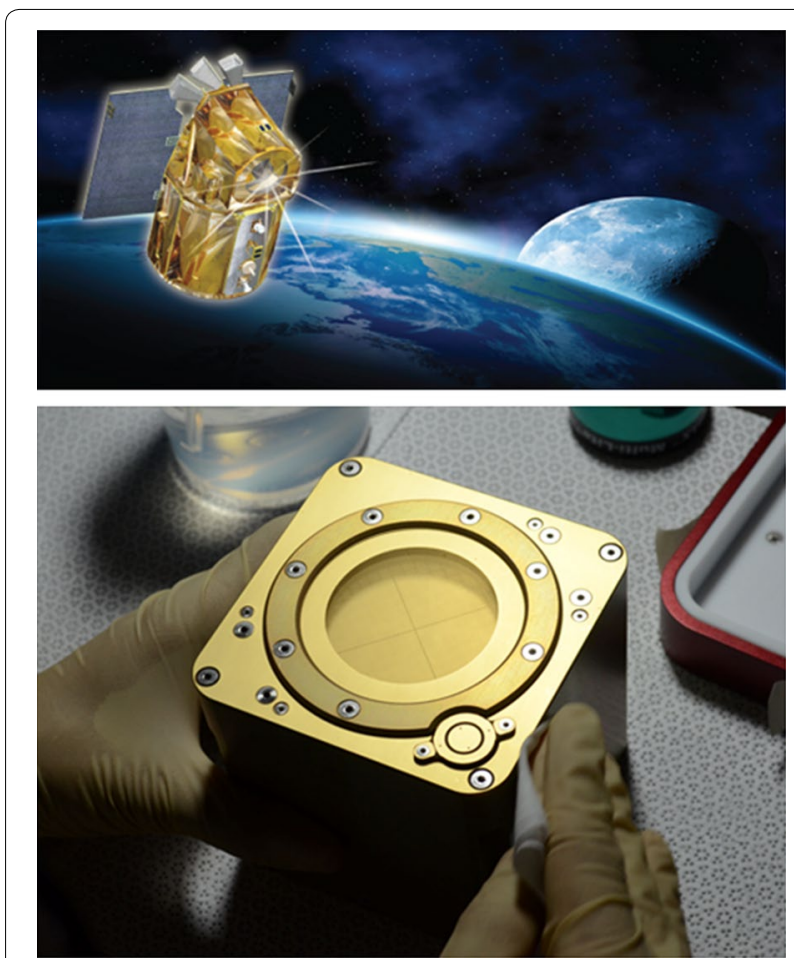

Fig. 5 Image of a flying simulation of FORMOSAT-5 and AIP

up to $8192 \mathrm{~S} / \mathrm{s}$ to measure ionospheric plasma concentrations $\left(N_{\mathrm{i}}\right)$, velocities $\left(V_{\mathrm{i}}\right)$, and temperatures $\left(T_{\mathrm{i}}\right.$ and $\left.T_{\mathrm{e}}\right)$ over a wide range of spatial scales in a time-sharing way (Fig. 5) (Chao et al. 2015).

AIP is a piggyback science payload developed by NCU for FORMOSAT-5 satellite to explore space weather and seismic precursors associated with strong earthquakes. The AIP is an all-in-one plasma sensor to measure ionospheric plasma concentrations, velocities, or temperatures in a time-sharing way. Meanwhile, the AIP is capable of measuring ionospheric plasma irregularities with sampling rate up to $8192 \mathrm{~Hz}$ over a wide range of spatial scales. Electroformed gold grids used in the AIP can reduce quasi-hysteresis effect on current-voltage curves in a plasma injection test and approximate ideal electrical potential surfaces for accurate data available in the future.

AIP is designed to meet science payload interface requirements of FORMOSAT-5 satellite and also to maximize geophysical parameters and data rates for science research. Under a 5-kg limit in mass, the AIP uses an all-in-one sensor configuration to measure ambient plasma concentrations, velocities, and temperatures but in a time-sharing manner. Most critical components of the AIP are redundantly implemented to achieve a 2-year mission lifetime. The AIP can continue on duty even if some components fail. However, at the beginning, the
AIP will be routinely operated within $\pm 75^{\circ}$ latitude in the nightside sector to meet a 5-W limit in average power per orbit due to high power consumption and a heat dissipation issue. Up to 1.5 gigabits per day in data storage, the AIP is capable to perform 8192 electric current readings per second with duty cycle under $10 \%$ to resolve fine structure of equatorial ionospheric plasma irregularities within $\pm 18^{\circ}$ latitude.

\section{FORMOSAT-7/(COSMIC-2)}

FORMOSAT-6 was designed to have a remote sensing mission and, however, terminated after a careful evaluation. FORMOSAT-7/COSMIC-2 (constellation observing system for meteorology, ionosphere and climate, here simplified as FORMOSAT-7) is an international collaboration between Taiwan (National Space Organization; NSPO) and the United States (National Oceanic and Atmospheric Administration; NOAA) that will use a constellation of twelve remote sensing microsatellites to collect atmospheric data for weather prediction and for ionosphere, climate, and gravity research. It is a followup mission to the FORMOSAT-3/COSMIC mission. The new constellation provides improved performance and a five times increase in number of measurements. The precision will also be improved. FORMOSAT-7 will establish operational mission of near real-numerical weather prediction. It will collect 8000 (threshold) profiles per day (the objective number is 10,000). NSPO will design, procure, integrate 12 spacecraft, and integrate the GNSS payload provided by JPL. The satellites have GPS, GALILEO, and GLONASS tracking capability. NOAA will procure the launch vehicles. The U.S. Air Force is partnering on COSMIC-2 and will provide two space weather payloads that will fly on the first six satellites: RF beacon transmitters and velocity, ion density, and irregularities (VIDI) instruments. The first launch of six satellites of the low inclination constellation is planned for 2016, and the second launch into the high inclination orbits will take place in 2018. The last launch includes a seventh backup satellite. FORMOSAT-7 shall make the ionospheric weather monitoring and forecast on three-dimensional electron density structure and dynamics being possible (Lee et al. 2013c).

\section{Ionospheric weather}

The ionospheric climate, which is usually the overall feature, averaged over a period of several years or decades. In contrast, the ionospheric weather is the shortterm variations in minutes to weeks. The ionospheric is becoming more relevant to human society with its reliance on modern technology, since the accuracy of positioning and navigation, and quality of telecommunication are influenced by ionospheric weather conditions from 
space (solar flare, eclipse, solar wind, magnetic storm, and so on), earth's atmosphere (sudden stratosphere warming), and lithosphere (earthquake and tsunami).

Liu et al. (2004a) developed the theory and the observation technique for monitoring ionospheric solar flare effects by means of the TEC recorded by ground-based GPS receivers. The development resulted in the finding that the ionospheric solar flare effect is a function the cosine of the great circle angle between the center and flare locations on the solar disk (Liu et al. 2006d). Liu et al. (2011c) found the solid evidence that Moon's shadow of the solar eclipse can trigger the atmospheric gravity waves, which in turn form the bow wave, the stern wave, and the stern wake in the atmosphere and ionosphere, since the bow wave was predicted in 1970 . Sun et al. $(2012,2013)$ showed the ionospheric plasma density irregularities response to magnetic storms. The results can help us to hypothesize the possible behavior of irregularities after storm onsets. Liu et al. (2016) surveyed the worst-case GPS scintillations on the ground estimated from radio occultation observations of $\mathrm{F} 3 / \mathrm{C}$ during 2007-2014 and are ready to develop an empirical model for the ionospheric S4 scintillation. Currently, the nowcast and forecast data assimilation models with the neutral atmosphere have been developed (Lee et al. 2012c; Hsu et al. 2014; Sun et al. 2015).

\section{Education of solar terrestrial sciences}

Education is a key driver for the scientific development. The space division of the Department of Atmospheric Sciences and the Institute of Space Science at National Central University has been carrying out the undergraduate and MS/Ph.D. graduate programs for solar terrestrial sciences since 1990. Currently, 15 full-time professors and six adjunct professors at the Institute of Space Science incubate 37 undergraduate students per year for the Department of Atmospheric Sciences and about 5 Ph.D./25 MS graduate students per year for its own institute. Main courses consist of seminar, special topics, applied mathematics, classical electromagnetics, space physics, ionospheric physics, magnetospheric physics, magnetohydrodynamics, space plasma physics, plasma measurement (satellite payload engineering), random process and spectral analysis, numerical simulation, principle of radar remote sensing, and digital image processing. In total, 62 Ph.D. and 425 MS students have graduated from the Institute of Space Science, and about one-third of them are in universities and research institutes. In general, the Institute of Space Science has five research directions of space physics, ionospheric physics, radar science, space payload, and remote sensing to provide/support Ph.D./MS research works/topics. This results in 123 journal papers being published in recent 3 years.

\section{Summary}

This paper summarizes the development of solar terrestrial sciences in Taiwan since 1952. It can be seen that since 1985, the modern technology and major facilities, such as ground-based GPS receivers, ChungLI VHF, and especially FORMOSAT satellites together with theoretical and model developments significantly boost the solar terrestrial science research in Taiwan. Meanwhile, since 1990 (1972), the education of NCU/ISS (NCU/ATM), which has incubated about 500 Masters/Doctors (1000+ Bachelors), should play an important role in development of solar terrestrial sciences for research areas from the Sun, solar wind, magnetosphere, ionosphere, and atmosphere, with theoretical developments, numerical simulations, and observations.

\section{Authors' contributions}

Based on the published papers and the materials provided by coauthors at National Central University and National Cheng Kung University, JYL summarizes their works and develops the manuscript. All authors read and approved the final manuscript.

\section{Author details}

${ }^{1}$ National Central University, Taoyuan, Taiwan. ${ }^{2}$ National Cheng Kung University, Tainan, Taiwan.

\section{Acknowledgements}

The authors wish to thank the session convener Prof. Balan N for inviting us to submit this paper. The authors wish to thank Dr. Lin C Y and Dr. Sun Y Y at NCU/ISS for scientific editing.

\section{Competing interests}

The author declares that they have no competing interests.

Received: 31 December 2015 Accepted: 19 May 2016

Published online: 23 June 2016

\section{References}

Chang SC, Kuo CL, Lee LJ, Chen AB, Su HT, Hsu RR, Frey HU, Mende SB, Takahashi Y, Lee LC (2010) ISUAL far-ultraviolet events, elves, and lightning current. J Geophys Res 115:A00E46. doi:10.1029/2009ja014861

Chang LC, Lin CH, Liu JY, Nanan B, Yue J, Lin JT (2013a) Seasonal and local time variation of ionospheric migrating tides in 2007-2011 FORMOSAT-3/ COSMIC and TIE-GCM total electron content. J Geophys Res Sp Phys 118:2545-2564. doi:10.1002/jgra.50268

Chang LC, Lin CH, Yue J, Liu JY, Lin JT (2013b) Stationary planetary wave and nonmigrating tidal signatures in ionospheric wave-3 \& Wave-4 variations in 2007-2011 FORMOSAT-3/COSMIC observations. J Geophys Res Sp Phys 118:6651-6665. doi:10.1002/jgra.50583

Chang LC, Yue J, Wang W, Wu Q, Meier RR (2014) Quasi-two day wave related variability in the background dynamics and composition of the mesosphere/thermosphere, and the ionosphere. J Geophys Res Sp Phys 119:4786-4804. doi:10.1002/2014JA019936

Chang LC, Liu H, Miyoshi Y, Chen CH, Chang FY, Lin CH, Liu JY, Sun YY (2015a) Structure and origins of the Weddell sea anomaly from tidal and planetary wave signatures in FORMOSAT-3/COSMIC observations and GAIA GCM simulations. J Geophys Res Sp Phys 120:1325-1340. doi:10.1 002/2014JA020752

Chang FY, Liu JY, Chang LC, Lin CH, Chen CH (2015b) Three-dimensional electron density along the WSA and MSNA latitudes probed by FORMOSAT-3/COSMIC. Earth Planets Sp 67:1-8. doi:10.1186/s40623-015-0326-8 
Chao CK, Su SY, Yeh HC (2003) Presunrise ion temperature enhancement observed at $600 \mathrm{~km}$ low- and mid-latitude ionosphere. Geophys Res Lett 30(4):1187. doi:10.1029/2002GL016268

Chao CK, Su SY, Yeh HC (2004) Ion temperature crests and troughs in the morning sector of the low-latitude and midlatitude topside ionosphere. J Geophys Res 109:A11303. doi:10.1029/2003JA010360

Chao CK, Su SY, Huba JD, Oyama KI (2010) Modeling the presunrise plasma heating in the low- to midlatitude topside ionospheres. J Geophys Res 115:A09304. doi:10.1029/2009JA014923

Chao CK, Lin ZW, Mao YC, Chang YS (2015) System architecture of advanced ionospheric probe onboard FORMOSAT-5 satellite. submitted to TAO

Chen KY, Yeh HC, Su SY, Liu CH, Huang NE (2001) Anatomy of plasma structures in an equatorial spread F event. Geophys Res Lett 28(16):3107-3110

Chen KY, Su SY, Liu CH, Basu S (2005) Ionospheric irregularity characteristics from quasiperiodic structure in the radio wave scintillation. Radio Sci 40:RS3001. doi:10.1029/2004RS003178

Chen B et al (2008) Global distributions and occurrence rates of transient luminous events. J Geophys Res 113:A08306. doi:10.1029/2008JA013101

Chen CH, Huba JD, Saito A, Lin CH, Liu JY (2011) Theoretical study of the ionospheric Weddell sea anomaly using SAMI2. J Geophys Res 116:A04305. doi:10.1029/2010JA015573

Chen CH, Lin CH, Chang LC, Huba JD, Lin JT, Saito A, Liu JY (2013) Thermospheric tidal effects on the ionospheric midlatitude summer nighttime anomaly using SAMI3 and TIEGCM. J Geophys Res Sp Phys 118(6):3836-3845. doi:10.1002/jgra.50340

Chen JS, Furumoto J, Yamamoto M (2014a) Three-dimensional radar imaging of atmospheric layer and turbulence structures using multiple receivers and multiple frequencies. Ann Geophys 32:899-909

Chen JS, Su CL, Chu YH, Kuong RM, Furumoto J (2014b) Measurement of range-weighting function for range imaging of $\mathrm{VHF}$ atmospheric radars using range oversampling. J Atmos Ocean Technol 31:47-61. doi:10.1175/JTECH-D-12-00236.1

Chen YT, Lin CH, Chen CH, Liu JY, Huba JD, Chang LC, Lin JT, Liu H, Rajesh PK (2014c) Theoretical study of the ionospheric plasma cave in the equatorial ionization anomaly region. J Geophys Res 119(12):10324-10335

Chen JS, Tsai SC, Su CL, Chu YH (2015) Evaluation of multifrequency rangeimaging technique implemented on the Chung-Li VHF atmospheric radar. Atmos Meas Tech Discuss 8:10097-10120

Chou JK et al (2010) Gigantic jets with negative and positive polarity streamers. J Geophys Res 115(A7):A00E45. doi:10.1029/2009JA014831

Chu YH, Brahmanandam PS, Wang CY, Su CL, Kuong RM (2011) Coordinated sporadic E layer observations made with Chung-Li $30 \mathrm{MHz}$ radar, ionosonde and FORMOSAT-3/COSMIC satellites. J Atmos Solar-Terr Phys 73:883-894

Chu YH, Yang KF, Wang CY, Su CL (2013) Meridional electric fields in layer-type and clump-type plasma structures in midlatitude sporadic E region: observations and plausible mechanisms. J Geophys Res Sp Phys 118:1243-1254. doi:10.1002/jgra.50191

Chu YH, Wang CY, Wu KH, Chen KT, Tzeng KJ, Su CL, Feng W, Plane JMC (2014) Morphology of sporadic E layer retrieved from COSMIC GPS radio occultation measurements: wind shear theory examination. J Geophys Res Sp Phys 119:2117-2136. doi:10.1002/2013JA019437

Das U, Pan, CJ (2014) Validation of FORMOSAT-3/COSMIC level 2 "atmPrf" global temperature data in the stratosphere. Atmo Measure Tech 7:731-742. doi:10.5194/amt-7-731-2014

Forbes JM, Bruinsma SL, Oberheide J, Zhang X (2009) Surface-exosphere coupling due to thermal tides. Geophys Res Lett 36:2009GL15812. doi:10.1029/L038748

Hsu CT, Matsuo T, Wang W, Liu JY (2014) Effects of inferring unobserved thermospheric and ionospheric state variables by using an Ensemble Kalman Filter on global ionospheric specification and forecasting. J Geophys Res Sp Phys 119:9256-9267. doi:10.1002/2014JA020390

Huang CM (2013) Disturbance dynamo electric fields in response to geomagnetic storms occurring at different universal times. J Geophys Res. doi:1 $0.1029 / 2012$ JA018118

Huang CM, Chen MQ (2008) Formation of maximum electric potential at the geomagnetic equator by the disturbance dynamo. J Geophys Res 113:A03301. doi:10.1029/2007JA012843

Huang CM, Richmod AD, Chen MQ (2005) Theoretical effects of geomagnetic activity on low-latitude ionospheric electric fields. J Geophys Res 110:A05312. doi:10.1029/2004JA010994
Huang CM, Chen MQ, Su SY (2008) Plasma drift observations associated with intense magnetic storms by the IPEI on board ROCSAT-1. J Geophys Res 113:A11301. doi:10.1029/2008JA013405

Huang CM, Chen MQ, Liu JY (2010) lonospheric positive storm phases at the magnetic equator close to sunset. J Geophys Res 115:A07315. doi:10.10 29/2009JA014936

Jao CS, Hau LN (2015) Two-dimensional electrostatic solitary structures in electron-positron plasmas. New J Phys 17:053047. doi:10.1088/1367-2630/17/5/053047

Kan JR, Li H, Wang C, Frey HU, Kubyshkina MV, Runov A, Xiao CJ, Lyu LH, Sun W (2011) Brightening of onset arc precedes the dipolarization onset: THEMIS observations of two events on 1 March 2008. Ann Geophys 29:2045-2059. doi:10.5194/angeo-29-2045-2011

Kuo CL, Chen AB, Chou JK, Tsai LY, Hsu RR, Su HT, Frey HU, Mende SB, Takahashi Y, Lee LC (2008) Radiative emission and energy deposition in transient luminous events. J Phys D 41:4014. doi:10.1088/0022-3727/41/23/234014

Kuo CL, Huba JD, Joyce G, Lee LC (2011) lonosphere plasma bubbles and density variations induced by pre-earthquake rock currents and associated surface charges. J Geophys Res 116:A10317

Kuo CL, Lee LC, Huba JD (2014) An improved coupling model for the lithosphere-atmosphere-ionosphere system. J Geophys Res 119:3189-3205

Lee LC, Wu CS (1980) Amplification of radiation near cyclotron frequency due to electron population inversion. Phys Fluids 23:1348

Lee CC, Liu JY, Chen MQ, Su SY, Yeh HC, Nozaki K (2004) Observation and model comparisons of the traveling atmospheric disturbances over the Western Pacific region during the 6-7 April 2000 magnetic storm. J Geophys Res 109:A09309. doi:10.1029/2003JA010267

Lee CC, Su SY, Reinisch BW (2005a) Concurrent study of bottomside spread F and plasma bubble events in the equatorial ionosphere during solar maximum using digisonde and ROCSAT-1. Ann Geophys 23:3473-3480. doi:10.5194/angeo-23-3473-2005

Lee CC, Liu JY, Reinisch BW, Chen WS, Chu FD (2005b) The effects of the prereversal drift, the EIA asymmetry, and magnetic activity on the equatorial spread F during solar maximum. Ann Geophys 23:745-751

Lee IT, Liu JY, Lin CH, Oyama Kl, Chen CY, Chen CH (2012a) lonospheric plasma caves under the equatorial ionization anomaly. J Geophys Res 117:A11309. doi:10.1029/2012JA017868

Lee IT, Matsuo T, Richmond AD, Liu JY, Wang W, Lin CH, Anderson JL, Chen MQ (2012b) Assimilation of FORMOSAT-3/COSMIC electron density profiles into a coupled thermosphere/ionosphere model using ensemble Kalman filtering. J Geophys Res 117:A10318. doi:10.1029/2 012JA017700

Lee KH, Omura Y, Lee LC (2012c) Electron acceleration by Z-mode waves associated with cyclotron maser instability. Phys Plasmas 19:122902

Lee IT, Tsai HF, Liu JY, Lin CH, Matsuo T, Chang LC (2013a) Modeling impact of FORMOSAT-7/COSMIC-2 mission on ionospheric space weather monitoring. J Geophys Res 118:6518-6523. doi:10.1002/jgra.50538

Lee KH, Omura Y, Lee LC (2013b) Electron acceleration by Z-mode and whistler-mode waves. Phys Plasmas 20:112901

Lee $L$ et al (2013c) Secondary gigantic jets as possible inducers of sprites. Geophys Res Lett 40(8):1462-1467. doi:10.1002/grl.50300

Lin CH (2014) A statistical study of the subsurface structure and eruptivity of solar active regions. Astrophys Sp Sci 352:361-371. doi:10.1007/ s10509-014-1931-x

Lin CH, Wang WB, Hagan ME, Hsiao CC, Immel TJ, Hsu ML, Liu JY, Paxton LJ, Fang TW, Liu CH (2007a) Plausible effect of atmospheric tides on the equatorial ionosphere observed by the FORMOSAT-3/COSMIC: threedimensional electron density structures. Geophys Res Lett 34:L11112. doi:10.1029/2007GL029265

Lin CH, Hsiao CC, Liu JY, Liu CH (2007b) Longitudinal structure of the equatorial ionosphere: time evolutions of the four-peaked EIA structures. J Geophys Res 112:A12305. doi:10.1029/2007JA012455

Lin CH, Liu JY, Cheng CZ, Chen CH, Liu CH, Wang W, Burns AG, Lei J (2009) Three-dimensional ionospheric electron density structure of the Weddell sea anomaly. J Geophys Res 114:A02312. doi:10.1029/200 8JA013455

Lin CH, Liu CH, Liu JY, Chen CH, Burns AG, Wang W (2010) Midlatitude summer nighttime anomaly of the ionospheric electron density observed by FORMOSAT-3/COSMIC. J Geophys Res 115:A03308. doi:10.1029/200 9JA014084 
Lin JT, Lin CH, Chang LC, Huang HH, Liu JY, Chen AB, Chen CH, Liu CH (2012) Observational evidence of ionospheric migrating tide modification during the 2009 stratospheric sudden warming. Geophys Res Lett 39:L02101. doi:10.1029/2011GL050248

Lin CH, Lin JT, Chang LC, Chen WH, Chen CH, Liu JY (2013) Stratospheric sudden warming effect on the ionospheric migrating tides during 2008-2010 observed by FORMOSAT-3/COSMIC. J Atmo Solar Terr Phys 103:SI66-SI75. doi:10.1016/j.jastp.2013.03.026

Liu JY, Sun YY (2011) Seismo-traveling ionospheric disturbances of ionograms observed during the 2011 Mw 9.0 Tohoku Earthquake. Earth Planets Sp 63:897-902

Liu JY, Chen YI, Chuo YJ, Tsai HF (2001) Variations of ionospheric total electron content during the Chi-Chi earthquake. Geophys Res Lett 28:1383-1386

Liu JY, Lin CH, Tsai HF, Liou YA (2004a) Ionospheric solar flare effects monitored by the ground-based GPS receivers: theory and observation. J Geophys Res 109:A01307. doi:10.1029/2003JA009931

Liu JY, Chuo YJ, Shan SJ, Tsai YB, Chen YI, Pulinets SA, Yu SB (2004b) Preearthquake ionospheric anomalies registered by continuous GPS TEC measurement. Ann Geophys 22:1585-1593

Liu JY, Chen CH, Chen YI, Yen HY, Hattori K, Yumoto K (2006a) Seismo-geomagnetic anomalies and $M \geq 5.0$ earthquakes observed in Taiwan during 1988-2001. Phys Chem Earth 31:215-222

Liu JY, Tsai YB, Chen SW, Lee CP, Chen YC, Yen HY, Chang WY, Liu C (2006b) Giant ionospheric disturbances excited by the M9.3 Sumatra earthquake of 26 December 2004. Geophys Res Lett 33:2005GL02103. doi:10.1029/L023963

Liu JY, Tsai YB, Ma KF, Chen YI, Tsai HF, Lin CH, Kamogawa M, Lee CP (2006c) Ionospheric GPS total electron content (TEC) disturbances triggered by the 26 December 2004 Indian ocean tsunami. J Geophys Res 111:A05303. doi:10.1029/2005JA011200

Liu JY, Lin CH, Chen YI, Lin YC, Fang TW, Chen CH, Chen YC, Hwang JJ (2006d) Solar flare signatures of the ionospheric GPS total electron content. J Geophys Res 111:A05308. doi:10.1029/2005JA011306

Liu JY, Chen YI, Chen CH, Liu CY, Chen CY, Nishihashi M, Li JZ, Xia YQ, Oyama KI, Hattori K, Lin CH (2009) Seismo-ionospheric GPS total electron content anomalies observed before the 12 May 2008 Mw7.9 Wenchuan earthquake. J Geophys Res 114:A04320. doi:10.1029/2008JA013698

Liu JY, Chen YI, Chen CH, Hattori K (2010a) Temporal and spatial precursors in the ionospheric global positioning system (GPS) total electron content observed before the 26 December 2004 M9.3 Sumatra-Andaman erthquake. J Geophys Res 115:2010JA09312. doi:10.1029/A015313

Liu JY, Chen CH, Chen Yl, Yang WH, Oyama KI, Kuo KW (2010b) A statistical study of ionospheric earthquake precursors monitored by using equatorial ionization anomaly of GPS TEC in Taiwan during 2001-2007. J Asian Earth Sci 39:76-80

Liu JY, Lin CY, Lin CH, Tsai HF, Solomon SC, Sun YY, Lee IT, Schreiner WS, Kuo YH (2010c) Artificial plasma cave in the low-latitude ionosphere results from the radio occultation inversion of the FORMOSAT-3/COSMIC. J Geophys Res 115:A07319. doi:10.1029/2009JA015079

Liu JY, Le H, Chen YI, Chen CH, Liu L, Wan W, Su YZ, Sun YY, Lin C, Chen MQ (2011a) Observations and simulations of seismoionospheric GPS total electron content anomalies before the 12 January 2010 M7 Haiti earthquake. J Geophys Res 116:A04302. doi:10.1029/2010JA015704

Liu JY, Chen CH, Lin CH, Tsai HF, Chen CH, Kamogawa M (2011b) lonospheric disturbances triggered by the 11 March 2011 M9.0 Tohoku earthquake. J Geophys Res 116:A06319. doi:10.1029/2011JA016761

Liu JY, Sun YY, Kakinami Y, Chen CH, Lin CH, Tsai HF (2011c) Bow and stern waves triggered by the Moon's shadow boat. Geophys Res Lett 38:L17109. doi:10.1029/2011GL048805

Liu JY, Chang FY, Oyama KI, Kakinami Y, Yeh HC, Yeh TL, Jiang SB, Parrot M (2015) Topside ionospheric electron temperature and density along the Weddell Sea latitude. J Geophys Res Sp Phys 120:609-614. doi:10.1002 /2014JA020227

Liu JY, Chen SP, Yeh WH, Tsai HF, Rajesh PK (2016) Worst-case GPS scintillations on the ground estimated from radio occultation observations of FORMOSAT-3/COSMIC during 2007-2014. Surv Geophys. doi:10.1007/ s10712-015-9355-x

Macalalad EP, Tsai LC, Wu J, Liu CH (2012) Application of the TaiWan ionosphere model to single-frequency ionospheric delay corrections for GPS positioning. GPS Solut. doi:10.1007/s10291-012-0282-8
Macalalad EP, Tsai LC, Wu J (2014) Performance evaluation of different ionospheric models in single-frequency code-based differential GPS positioning. GPS Solut. doi:10.1007/s10291-014-0422-4

Oyama KI, Kakinami Y, Liu JY, Kamogawa M, Kodama T (2008) Reduction of electron temperature in low-latitude ionosphere at $600 \mathrm{~km}$ before and after large earthquakes. J Geophys Res 113:A11317. doi:10.1029/200 8JA013367

Oyama KI, Kakinami Y, Liu JY, Abdu MA, Cheng CZ (2011) Latitudinal distribution of anomalous ion density as a precursor of large earthquake. J Geophys Res 116:A04319. doi:10.1029/2010JA015948

Pan CJ, Das U, Yang SS, Wong CJ, Lai HC (2011) Investigation of Kelvin waves in the stratosphere using FORMOSAT-3/COSMIC temperature data. J Meteor Soc Japan 89(1 A):337-350

Shue JH, Chao JK (2013) The role of enhanced thermal pressure in the earthward motion of the earth's magnetopause. J Geophys Res Sp Phys 118:3017-3026. doi:10.1002/jgra.50290

Shue JH et al (2011) Uneven compression levels of earth's magnetic fields by shocked solar wind. J Geophys Res 116:A02203. doi:10.1029/201 OJA016149

Shue JH, Hsieh YK, Tam SWY, Wang K, Fu HS, Bortnik J, Tao X, Hsieh WC, Pi G (2015) Local time distributions of repetition periods for rising tone lower band chorus waves in the magnetosphere. Geophys Res Lett 42:8294-8301. doi:10.1002/2015GL066107

Su SY, Yeh HC, Heelis RA (2001) ROCSAT 1 ionospheric plasma and electrodynamics instrument observations of equatorial spread F: an early transitional scale result. J Geophys Res 106(A12):29153-29159. doi:10.1 029/2001JA900109

Su SY, Yeh HC, Chao CK, Heelis RA (2002) Observation of a large density dropout across the magnetic field at $600 \mathrm{~km}$ altitude during the 6-7 April 2000 magnetic storm. J Geophys Res 107(A11):1404. doi:10.1029/ 2001JA007552

Su SY, Chao CK, Yeh HC, Heelis RA (2003) Observations of shock impact, disturbance dynamo effect, and a midlatitude large-density depletion at $600 \mathrm{~km}$ altitude on the 17 April 2002 storm day. J Geophys Res 108(A8):1310. doi:10.1029/2002JA009752

Su SY, Yeh HC, Chao CK, Heelis RA (2004) Supercooled ion temperatures observed in the topside ionosphere at dawn meridian during storm periods. J Geophys Res 109:A06307. doi:10.1029/2003JA010139

Su SY, Chen KY, Wu JM, Yeh HC, Chao CK (2005a) ROCSAT observation of the field line resonance effect in a plasma pulsation at topside ionosphere. J Geophys Res 110:A01303. doi:10.1029/2004JA010539

Su SY, Chao CK, Yeh HC, Heelis RA (2005b) Seasonal and latitudinal distributions of the dominant light ions at $600 \mathrm{~km}$ topside ionosphere from 1999 to 2002. J Geophys Res 110:A01302. doi:10.1029/200 4JA010564

Su SY, Liu CH, Ho HH, Chao CK (2006) Distribution characteristics of topside ionospheric density irregularities: equatorial vs. midlatitude regions. J Geophys Res 111:A06305. doi:10.1029/2005JA011330

Su SY, Chao CK, Liu CH, Ho HH (2007a) Meridional wind effect on anti-solar activity correlation of equatorial density irregularity distribution. J Geophys Res 112:A10305. doi:10.1029/2007JA012261

Su SY, Tsunoda RT, Liu CH, Chao CK, Wu JM (2007b) ROCSAT observations of topside ionospheric undulations and irregularities at low to middle latitudes. J Geophys Res 112:A11309. doi:10.1029/2007JA012371

Su SY, Chao CK, Liu CH (2008) On monthly/seasonal/longitudinal variations of equatorial irregularity occurrences and their relationship with the postsunset vertical drift velocities. J Geophys Res 113:A05307. doi:10.10 29/2007JA012809

Su SY, Chao CK, Liu CH (2009) Cause of different local time distribution in the postsunset equatorial ionospheric irregularity occurrences between June and December solstices. J Geophys Res 114:A04321. doi:10.1029/ 2008JA013858

Su SY, Chen MQ, Chao CK, Liu CH (2010) Global, seasonal, and local time variations of ion density structure at the low-latitude ionosphere and their relationship to the postsunset equatorial irregularity occurrences. J Geophys Res 115:A02309. doi:10.1029/2009JA014339

Su CL, Chen HC, Chu YH, Chung MZ, Kuong RM, Lin TH, Tzeng KJ, Wang CY, Wu $\mathrm{KH}$, Yang KF (2014) Meteor radar wind over Chung-Li $\left(24.9^{\circ} \mathrm{N}, 121^{\circ} \mathrm{E}\right)$, Taiwan, for the period 10-25 November 2012 which includes Leonid meteor shower: comparison with empirical model and satellite measurements. Radio Sci. doi:10.1002/2013RS005273 
Sun YY, Oyama Kl, Liu JY, Jhuang HK, Cheng CZ (2011) The neutral temperature in the ionospheric dynamo region and the ionospheric $\mathrm{F}$ region density during Wenchuan and Pingtung Doublet earthquakes. Nat Hazards Earth Syst Sci 11:1759-1768. doi:10.5194/nhess-11-1759-2011

Sun YY, Liu JY, Lin CH (2012) A statistical study of low latitude F region irregularities at Brazilian longitudinal sector response to geomagnetic storms during post-sunset hours in solar cycle 23. J Geophys Res 117:A03333. doi:10.1029/2011JA017419

Sun YY, Matsuo T, Araujo-Pradere EA, Liu JY (2013) Ground-based GPS observation of SED-associated irregularities over CONUS. J Geophys Res Sp Phys 118:2478-2489. doi:10.1029/2012JA018103

Sun YY, Matsuo T, Maruyama N, Liu JY (2015) Field-aligned neutral wind bias correction scheme for global ionospheric modeling at midlatitudes by assimilating FORMOSAT-3/COSMIC hmF2data under geomagnetically quiet conditions. J Geophys Res Sp Phys 120:3130-3149. doi:10.1002/2 014JA020768

Tsai LC, Liu CH, Hsiao TY, Huang JY (2009) A near real-time phenomenological model of ionospheric electron density based on GPS radio occultation data. Radio Sci. doi:10.1029/2009RS004154

Tsai LC, Kevin Chang K, Liu CH (2011) GPS radio occultation measurements on ionospheric electron density from low earth orbit. J Geodesy 85:941-948. doi:10.1007/s0019001104769

Tsai LC, Macalalad EP, Liu CH (2014a) TaiWan Ionospheric Model (TWIM) prediction based on time series autoregressive analysis. Radio Sci 49:977-986. doi:10.1002/2014RS005448

Tsai LC, Tien MH, Chen GH, Yali Zhang (2014b) HF radio angle-of-arrival measurements and ionosonde positioning. Terr Atmos Ocean Sci 25:401-413. doi:10.3319/TAO.2013.12.19.01(AA)
Wang BJ, Hau LN (2015) General formulation for electrostatic solitons in multicomponent nonthermal plasmas. Plasma Phys Control Fusion 57:095012. doi:10.1088/0741-3335/57/9/095012

Wang CY, Chu YH, Su CL, Kuong RM, Chen H-C, Yang KF (2011) Statistical investigations of layer-type and clump-type plasma structures of 3-m field-aligned irregularities in nighttime sporadic E region made with Chung-Li VHF radar. J Geophys Res 116:A12311. doi:10.1029/201 $1 \mathrm{JA0} 016696$

Weng CJ, Lee LC, Kuo CL, Wang CB (2013) Effects of ion-neutral collisions on Alfvén waves: the presence of forbidden zone and heavy damping zone. Phys Plasmas 20:032902

Wu CS, Lee LC (1979) A theory of the terrestrial kilometric radiation. Astrophys J 230:621

Wu YJ et al (2012) Occurrence of elves and lightning during El Niño and La Niña. Geophys Res Lett 39(3):L03106. doi:10.1029/2011GL049831

Wu KH, Su CL, Chu YH (2015) Improvement of GPS radio occultation retrieval error of E region electron density: COSMIC measurement and IRI model simulation. J Geophys Res Sp Phys 120:2299-2315. doi:10.1002/201 4JA020622

Xia YQ, Liu JY, Cui XY, Li JZ, Chen WS, Liu CY (2011) Abnormal Infrasound Signals before $92 \mathrm{M} \geqq 7.0$ Worldwide Earthquakes during 2002-2008. J Asian Earth Sci 41:434-441. doi:10.1016/j.jseaes

Yang YH, Chen PF, Hsieh MS, Wu ST, He H, Tsai TC (2014) Characteristics of photospheric magnetic field associated with solar flare initiation. Astrophys J. doi:10.1088/0004-637X/786/1/72

Yeh HC, Su SY, Heelis RA (2001) Storm time plasma irregularities in the predawn hours observed by the low-latitude ROCSAT- 1 satellite at $600 \mathrm{~km}$ altitude. Geophys Res Lett 28(4):685-688

\section{Submit your manuscript to a SpringerOpen ${ }^{\odot}$ journal and benefit from:}

- Convenient online submission

- Rigorous peer review

- Immediate publication on acceptance

- Open access: articles freely available online

- High visibility within the field

- Retaining the copyright to your article

Submit your next manuscript at springeropen.com 